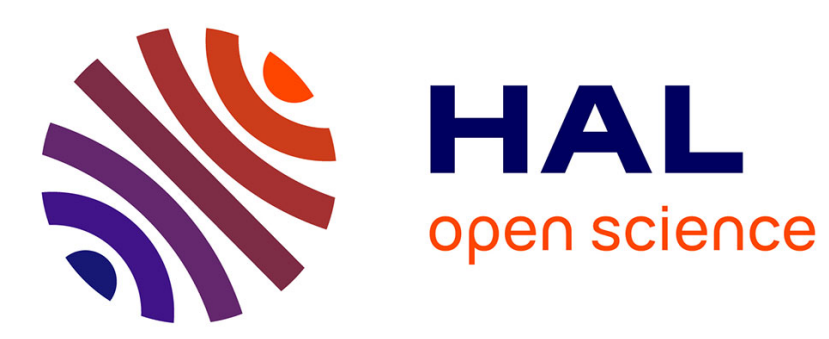

\title{
Supramolecular chiral self-assemblies of Gly-Pro dipeptides on metallic fcc(110) surfaces
}

C. Methivier, H. Cruguel, C.-M. Pradier, V. Humblot

\section{To cite this version:}

C. Methivier, H. Cruguel, C.-M. Pradier, V. Humblot. Supramolecular chiral self-assemblies of Gly-Pro dipeptides on metallic fcc(110) surfaces. Faraday Discussions, 2017, 204, pp.69-81. 10.1039/c7fd00116a . hal-01651983

\section{HAL Id: hal-01651983 https://hal.science/hal-01651983}

Submitted on 4 Jan 2018

HAL is a multi-disciplinary open access archive for the deposit and dissemination of scientific research documents, whether they are published or not. The documents may come from teaching and research institutions in France or abroad, or from public or private research centers.
L'archive ouverte pluridisciplinaire HAL, est destinée au dépôt et à la diffusion de documents scientifiques de niveau recherche, publiés ou non, émanant des établissements d'enseignement et de recherche français ou étrangers, des laboratoires publics ou privés. 


\title{
Supramolecular chiral self-assemblies of Gly-Pro dipeptides on metallic fcc(110) surfaces
}

\author{
C. Méthivier, ${ }^{a}$ H. Cruguel, ${ }^{b}$ C.-M. Pradier, ${ }^{a}$ and V. Humblot, ${ }^{a,+}$ \\ The adsorption of the Glycine-Proline (Gly-Pro) dipeptide has been investigated by surface science complementary \\ techniques on $\mathrm{Au}(110)$ and $\mathrm{Ag}(110)$, showing some interesting differences both in the chemical form and surface \\ organization of the adsorbed peptide. On $\mathrm{Au}(110)$, Gly-Pro mainly adsorbs under a neutral form $\left(\mathrm{COOH} / \mathrm{NH}_{2}\right)$, at low \\ coverage or for short time of interaction; the surface species become zwitterionic for higher coverage or longer time of \\ interaction. These changes are accompanied by a complete reorganization of the molecules at the surface. On $\mathrm{Ag}(110)$, \\ only anionic molecules $\left(\mathrm{COO}^{-} / \mathrm{NH}_{2}\right)$ were detected on the surface; and only one type of arrangement was observed. These \\ results will be compared to some previously obtained on $\mathrm{Cu}(110)$, thus providing a unique comparison of the adsorption of \\ the same di-peptide on three different metal surfaces; the great influence of the substrate on both the chemical form and \\ the arrangement of adsorbed di-peptides was made clear.
}

\section{Introduction}

Surface Science techniques enable the detailed characterization of model bio-interfaces, for instance the adsorption of amino acids or small peptides on model metal surfaces ${ }^{1-3}$. Adsorption of glycine, methionine $^{17}$, alanine ${ }^{3}$, glutamic acid ${ }^{37,38}$, lysine $e^{12,13} \ldots$. has been well described in the recent literature thanks to studies in UHV conditions and this, mainly on copper, less frequently on gold ; and very little studies on silver surfaces could be found ${ }^{4-19}$.

From these well documented studies, it appears that amino acids mostly undergo a deprotonation of their acid groups when interacting with copper ${ }^{4,12,13,20,21}$; they bind to the surface via the oxygen atoms of the carboxylate groups. Not similarly, such a deprotonation process is not systematic on gold; the latter metal seems also to favour an interaction of the $\mathrm{NH}_{2}$ group with the metal, inducing a well detectable electronic transfer from the $\mathrm{N}$ atom to the metal; the latter is evidenced by a shift of the XPS N1s peak at Binding Energy (BE) below $399.5 \mathrm{eV}^{17,22,23}$.

As for small peptides, the number of investigations addressing the issue of peptide interactions with metal surfaces is of course

\footnotetext{
${ }^{a}$ Sorbonne Universités, UPMC Université Pierre et Marie Curie, Univ Paris 6, Paris, FranceLaboratoire de Réactivité de Surface - UMR CNRS 7197, Université Pierre et Marie Curie, UPMC Paris 6, 4 place Jussieu, F-75005 Paris, France.

${ }^{b .}$ Sorbonne Universités, UPMC Université Pierre et Marie Curie, Univ Paris 6, Paris,

France, Institut des NanoScience de Paris, Université Pierre et Marie Curie, UPMC Paris 6, 4 place Jussieu, F-75005 Paris, France.
}

† corresponding author: vincent.humblot@upmc.fr

Electronic Supplementary Information (ESI) available: [details of any supplementary information available should be included here]. See DOI: $10.1039 / \times 0 \times x 00000 x$ smaller $^{24}$; the same tendencies can be deduced, an easy deprotonation of the acid groups on copper and a frequent interaction of nitrogen with gold; the image is however more complex having in mind that, for instance the GSH tri-peptide (GlyPro-Glu), preferentially interacts via its $S$ atoms at small coverages on gold ${ }^{25,26}$ and copper, that the Gly-Pro dipeptide was observed to bind via oxygen and nitrogen atoms on copper and overall, that the geometry, point of interaction, and sometime, the chemical form itself of the peptide vary with the coverage!

These findings originate from an examination of numerous studies addressing the interaction of one amino acid or of one peptide with a metal ... not from a rigorous comparison of the adsorption of one species with the surface of identical geometry but of various metals. This is precisely the objective of the present investigation where the di-peptide, Glycine-Proline (Gly-Pro), Cf. Figure 1, was adsorbed, under similar conditions on the $\mathrm{fcc}(110)$ surfaces of gold and silver.
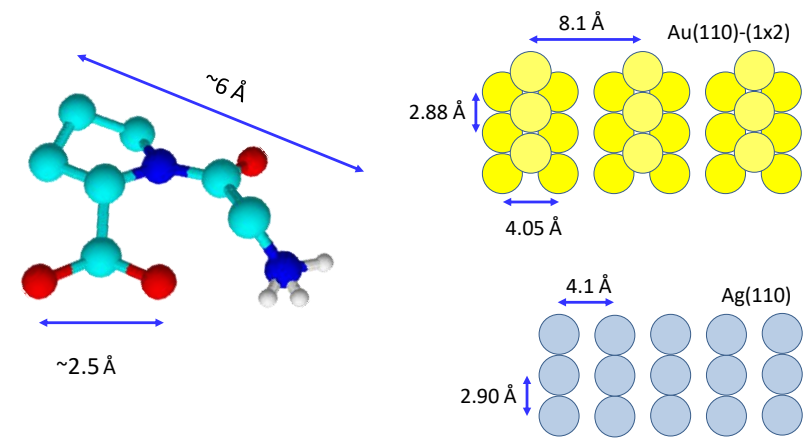

Figure 1: left, Molecular model for Gly-Pro under its zwitterionic chemical form together with calculated molecular dimensions in the gas phase; right atomic dimensions of $\mathrm{Au}$ and $\mathrm{Ag}$ surfaces. 
A variety of experimental surface science techniques of characterization have been applied, namely Modulation Polarisation Reflection Absorption Infrared Spectroscopy (PMRAIRS), X-ray Photoelectron Spectroscopy (XPS) and Scanning Tuneling Microscopy (STM). Let's underline that PM-RAIRS analyses were taken during the exposure to the Gly-Pro $\left(P=10^{-9}\right.$ Torr), while XPS and STM analyses were performed in another chamber.

The comparison will be enriched by the results of recent studies of the adsorption of the same dipeptide on $\mathrm{Cu}(110)^{23,27}$.

The Gly-Pro dipetide bears a nitrogen atom on its cycle, a $\mathrm{C}=\mathrm{O}$ amide groups and only one $\mathrm{COOH}-\mathrm{NH}_{2}$ groups; this makes the IR and XPS characteristic signals easily identified. And, as a matter of fact, on $\mathrm{Cu}(110)$, two binding points, the $\mathrm{COO}^{-}$groups and the $\mathrm{N}$ atom of $\mathrm{NH}_{2}$ groups, have been identified by combining PM-IRRAS and XPS. Importantly, long exposure (more than 60 min under $\mathrm{P}=$ $10^{-9}$ Torr) did not lead to form more than one saturated monolayer ${ }^{23}$.

One will see in the present work that, on $\mathrm{Au}(110)$, the Gly-Pro is mainly under a neutral or zwitterionic form; its orientation and surface organization are coverage and time-dependent forming line of dimers or trimmers first, followed by dense heptamers arrays; conversely, on $\mathrm{Ag}(110)$, one observes a significant deprotonation of the acid group thus leading to different mode of interaction with the surface. From low values of the coverage, Gly-Pro molecules form chiral domains on $\mathrm{Ag}(110)$ with the creation of "zig-zig like" lines of molecules.

\section{Results and discussion}

\section{Gly-Pro on $\mathrm{Au}(110)-(1 \times 2)$}

PM-IRRAS spectra of the Au surface (110) recorded with continuous exposure of Gly-Pro are shown in Figure SI1. After $10 \mathrm{~min}$ exposure (bottom spectrum) and $35 \mathrm{~min}$ of exposure (top spectrum), the peaks are not very intense, but are well defined. All bands increase with increasing exposure to Gly-Pro molecules, leading to the following main IR bands: the most intense observed at $1668 \mathrm{~cm}^{-1}$, is attributed to the elongation vibration $\mathrm{vC}=\mathrm{O}$ of the amide I bands; the features at 1723 and $1054 \mathrm{~cm}^{-1}$ are respectively assigned to the vibrations $\mathrm{VC}=\mathrm{O}$ and $\mathrm{vC}-\mathrm{OH}$ of the carboxylic acid groups, while the bands at 1596 and $1415 \mathrm{~cm}^{-1}$ are attributed respectively to the asymmetric and symmetric stretching of the carboxylate ( $\left.\mathrm{COO}^{-}\right)$ functions ${ }^{26}$. Moreover, the presence of lower absorption bands at 1645 and $1519 \mathrm{~cm}^{-1}$ can be attributed to asymmetric and symmetrical deformations of $\mathrm{NH}_{3}{ }^{+}$of the protonated amine groups, and finally a band observed at $1562 \mathrm{~cm}^{-1}$ is associated with the $\delta \mathrm{NH}_{2}$ deformation band ${ }^{12}$. This first result suggests the presence of several chemical species on the surface, most probably the coexistence of Gly-Pro molecules in the neutral $\mathrm{COOH} / \mathrm{NH}_{2}$ or anionic $\mathrm{NH}_{2} / \mathrm{COO}-$, and zwitterionic $\mathrm{NH}_{3}^{+} / \mathrm{COO}^{-}$forms.

The high resolution XPS spectra of the N1s and O1s core levels are shown in Figure 2 for two different exposure times: 10 and 35 minutes. Two contributions are identified in the N1s region of Gly-Pro at $400.2(\underline{400.4}) \pm 0.1 \mathrm{eV}$ and $401.6(\underline{402.1}) \pm 0.1 \mathrm{eV}$, which correspond, respectively to the nitrogen atoms in $\mathrm{NH}_{2}$ amine and $\mathrm{NH}$ amide groups, and $\mathrm{N}$ in $\mathrm{NH}_{3}{ }^{+}$protonated amine groups. The $\mathrm{O} 1 \mathrm{~s}$ region shows three contributions, at 531.5 $(\underline{531.7}) \pm 0.1 \mathrm{eV}, 532.4(\underline{532.6}) \pm 0.1 \mathrm{eV}$ and $533.5(\underline{533.7}) \pm 0.1$ $\mathrm{eV}$, attributed respectively to the oxygen atoms of deprotonated acid groups and of amides groups (COO / $\mathrm{HNC}=\mathrm{O}$ ), of the oxygen atoms of the protonated acid groups $((\mathrm{HO}-\mathrm{C}=\mathrm{O})$ and of the oxygen of the $\mathrm{OH}$ acid groups $(\mathrm{OH}-$ $\mathrm{C}=\mathrm{O})^{17,28,29}$. The presence of protonated acidic groups is confirmed by XPS data of the C1s region, Figure SI5, showing a contribution at high Binding Energy (BE), ca. $290 \mathrm{eV}$.

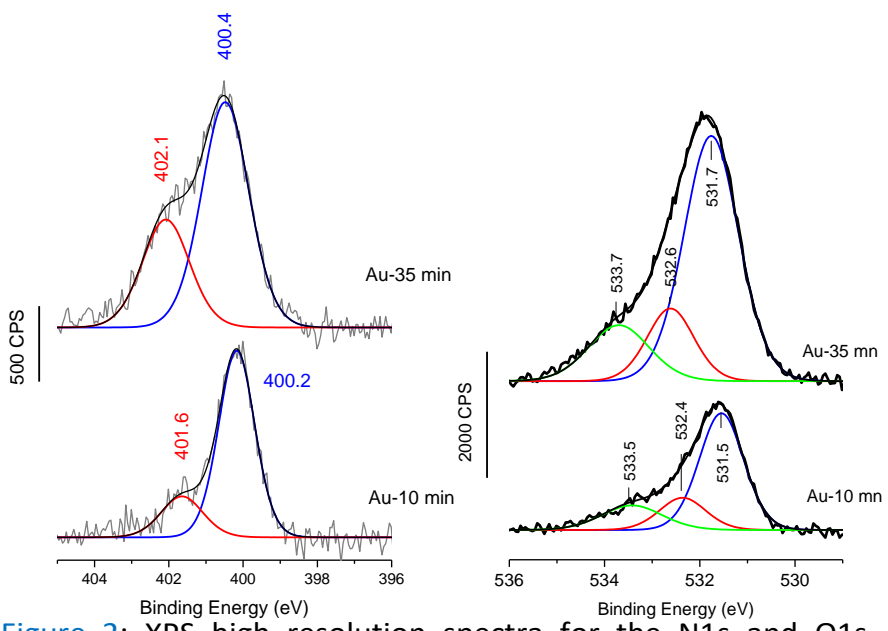
Figure 2: XPS high resolution spectra for the N1s and $01 \mathrm{~s}$ regions for a 10 and 35 minute dose of Gly-Pro adsorbed on $\mathrm{Au}(110)$.

Note that, the ratio of the $\mathrm{NH}_{3}{ }^{+} / \mathrm{NH}_{2}$ XPS contributions passes from $41 \%$ after 10 minutes of exposure to nearly $65 \%$ after 35 minutes, $C f$. Table SI1, thus indicating a net increase of the zwitterionic species. Considering that, simultaneously, the fraction of the $\mathrm{O} 1 \mathrm{~s}$ contribution at higher BE $(533.2 \mathrm{eV})$ is quasi-constant, one must admit that, the fraction of zwitterionic molecules mainly increases at the expense of anionic molecules. One may even estimate that the fraction of latter decreases from 39 to $35 \%$. This is in agreement with the growth of the massif at ca $1723-1756 \mathrm{~cm}^{-1}$ which originates from the $\mathrm{C}=\mathrm{O}$ stretch of acid groups. As a matter of fact, looking now at the IR band intensities and their variations with time of exposure, helps understanding the adsorption process of Gly-Pro on $\mathrm{Au}(110)$, even if this task is rather complex due to the coexistence of several chemical species on the surface. Finally, XPS data also allow estimating the local coverage for both dosing time: after $10 \mathrm{~min}$, the local coverage is calculated at 1.6 molecules $/ \mathrm{nm}^{2}$, and 2.4 molecules $/ \mathrm{nm}^{2}$ after 35 minutes; knowing that a saturated monolayer is reached for a local coverage of $4 \mathrm{molecule} / \mathrm{nm}^{2}$, one can estimated the 
coverage to be around $40 \%$ and $60 \%$ of a sarurated monolayer respectively for 10 and 35 minutes.

We then investigated the possible 2D arrangements that the adsorption of Gly-Pro on Au (110)-(1x2) implies. Figure 3 shows STM data obtained after 10 minutes of dose, which distinctly show an arrangement in line along the [110] axis, and a second oblique arrangement located in between these lines of molecules. A first, one is tempted to believe that these two different 2D structures result from the adsorption of GlyPro under different chemical forms. Thus, by scanning the same given area, Figure $\mathrm{SI}$, the evolution of the $2 \mathrm{D}$ arrangements is clear, in particular, the mobility of the molecules constituting the linear arrangements, passing from simple lines to double or triple lines. Moreover, one can distinguish that the island of molecules having an oblique arrangement sees its area, and thus its number of molecules, increase as a function of the relaxation time (or time of observation); namely, the area is multiplied by 4 after 150 minutes without any further dosing. This allows us to conclude that the linear arrangements, forming first, are most likely made up of Gly-Pro molecules in the chemical neutral or anionic form; as a consequence, the oblique arrangement whose fraction increases with time is likely constituted of molecules of Gly-Pro in their zwitterionic form.

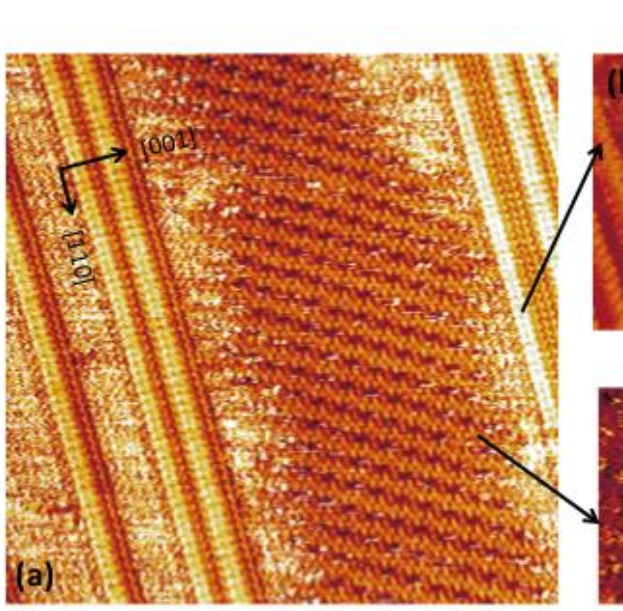

STM image: $50 \mathrm{~nm} \times 50 \mathrm{~nm}$
Gly-Pro Neutral

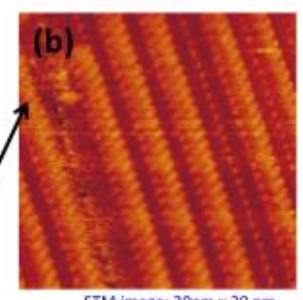

STM image: $20 \mathrm{~nm} \times 20 \mathrm{~nm}$

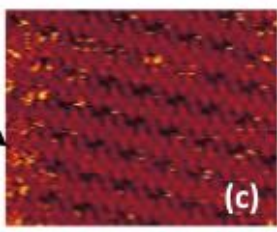

STM image: $12 \mathrm{~nm} \times 15 \mathrm{~nm}$
Gly-Pro Zwiterrionic

Figure 3: STM images showing the 2 domains of Gly-Pro coexisting in surfaces in (a), and each of the domains separated in (b) Gly-Pro in the neutral and anionic forms and (c) Gly-Pro in zwitterionic form.

We then analyzed each of these 2D arrangements in greater detail. Figure 3 (a) shows STM images where the lines of molecules that appear to be organized in groups of at least two lines are seen in more detail, while for the oblique 2D arrangement, small groups of molecules self-organize with an angle of $30^{\circ}$ with the main [001] crystallographic axis. In the case of the Gly-Pro molecule in its chemical neutral/anionic forms, Figure 3 (b), the in-line arrangement is reminiscent of that already observed in the case of Gly-Pro on $\mathrm{Cu}(110)^{27}$. By measuring the distances between the lines and between each of the neutral Gly-Pro molecules, the latter are organized in lines of 2 or 3 units, with a non-chiral 2D repeating pattern, similar to a rectangular unit cell $(3 \times 6)$, Figure $4(a)$.

From XPS data, we were able to estimate the average thickness from the adlayer after 10 minutes of dose; the thickness was estimated at $0.3 \mathrm{~nm}$ that corresponds to about 1.6 Gly-Pro molecules $/ \mathrm{nm}^{2}$, which slightly overestimates what can be seen on the model of Figure 4 (a) with a bit more than one molecule within $1 \mathrm{~nm}^{2}$ dash line square. Let's recall that the model presented is only for double lines, knowing from the STM images that they could be triple lines or more.

Turning now to the second 2D structure created by Gly-Pro in its zwitterionic chemical form, Figure 3(c), we realize the complexity of the 2D arrangement composed of an hexagonal structure with repetitive patterns along two non-orthogonal axes and desoriented with respect to the crystallographic axes; this last point suggests the creation of a chiral over-structure created by the zwitterionic Gly-Pro. Measurements taken on the STM images allow us to have more information on the intermolecular spacing and on the position of the atoms with respect to the gold surface. Molecules of Gly-Pro are organized in hexagonal arrangements, around a central molecule, thus creating groups of heptamers, Figure 4(b). A particular colour code has been used in this adsorption model to ease to reader to visualize the heptamer unique formation. One should note that all GP molecules are equivalents regardless of the colour which represents them. Nevertheless, a group of 4 molecules painted in blue seems to compose the centre of the heptamer motif, while the red and green molecules composed the surrounding GP forming the hexagonal patches. Finally, it can be noted that in the model depicted in Figure $4(\mathrm{~b})$, one green GP molecule is not part of any heptamer, but is centred in the middle of 4 hexagonal groups, possibly suggesting a more complex organisation within the GP film. In addition, these heptamers are themselves organized in a chiral unit cell identified as a $(45,-61)$ unit cell. One may probably say that surface chirality is expressed in two ways in this 2D arrangement, both within a given heptamer group and at the extended level of the heptamer arrays. Again, from XPS data, we were able to estimate the average thickness after 35 minutes of dose to $0.46 \mathrm{~nm}$ that corresponds to about 2.4 GlyPro molecules $/ \mathrm{nm}^{2}$, or around 3 molecules within the square depicted on the model of Figure 4 (b).

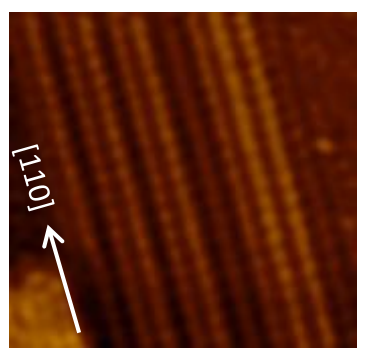

(a)

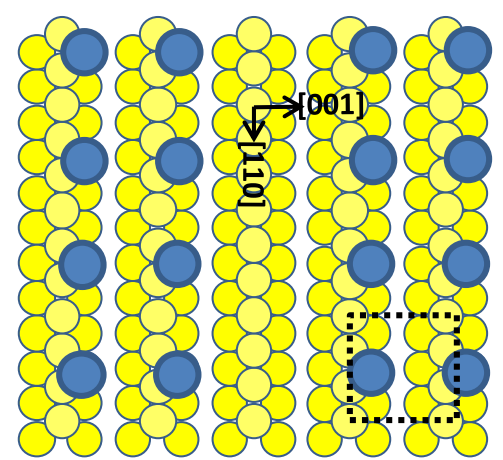




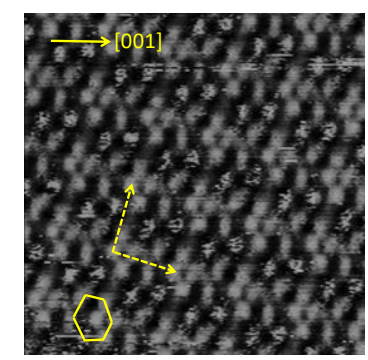

(b)

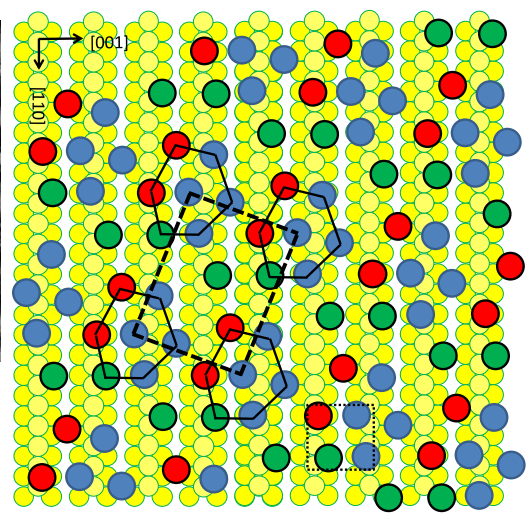

Figure 4: (a) adsorption model for Gly-Pro adsorbed as neutral molecules on $\mathrm{Au}(110)$ showing a $(3 \times 6)$ unit cell. Insert shows the corresponding STM image. (b) adsorption model for GlyPro adsorbed as zwitterionic molecules on $\mathrm{Au}(110)$ showing a complex chiral $(45,-61)$ unit cell composed of heptamers of Gly-Pro molecules arranged as distorded hexagonal motif. Insert shows the corresponding STM images. On both schematic adsorption models, the dash square line represents an area of $1 \mathrm{~nm}^{2}$.

\section{Gly-Pro on $\mathrm{Ag}(110)$}

PM-RAIRS spectra of the $\mathrm{Ag}(110)$ surface recorded with continuous exposure of Gly-Pro are shown in Figure SI3. After $10 \mathrm{~min}$ exposure (bottom spectrum), the peaks are not very intense, but well defined. One can isolate two main features at 1383 and $1619 \mathrm{~cm}^{-1}$ assigned respectively to the symmetric and asymmetric stretching vibration of the deprotonated carboxylate group vCOO; the $\mathrm{\delta NH}_{2}$ signature is visible through a weak feature shouldered at $1619 \mathrm{~cm}^{-1}$. Finally others features associated to $\delta \mathrm{CH}_{2}$ and $v \mathrm{C}=\mathrm{O}$ of the amide bond are observed at $1457 \mathrm{~cm}^{-1}$ and $1651 \mathrm{~cm}^{-1}$, respectively. Taking into account the features and the absence of a spectral signature for free acidic groups $(\mathrm{COOH})$ and protonated amine groups $\left(\mathrm{NH}_{3}{ }^{+}\right)$, we can concluded that after 10 minutes of exposure of Gly-Pro on $\mathrm{Ag}(110)$, the molecules are mainly present as anionic species, $\mathrm{COO}^{-} / \mathrm{NH}_{2}$. Following coverage increase, the PM-RAIRS spectra profiles are changing with intensity increases together with the appearance of news feature, at $1693 \mathrm{~cm}^{-1}$ and $1550 \mathrm{~cm}^{-1}$. The first one is assigned to $\mathrm{vC}=\mathrm{O}$ of an acidic protonated group; the second feature can be the amide II band signature $(\mathrm{VCN}+\delta \mathrm{NH})$ which was not previously observed. We can therefore conclude, that within a monolayer of anionic Gly-Pro molecules $\left(\mathrm{COO}^{-} / \mathrm{NH}_{2}\right)$, a small fraction of neutral $\left(\mathrm{COOH} / \mathrm{NH}_{2}\right)$ molecules are present on the $\mathrm{Ag}$ surface.

High resolution XPS data have also been recorded at various coverages of Gly-Pro adsorbed on $\mathrm{Ag}(110)$. On Figure 5, the O1s region exhibits after 10 minutes a single peak at $531.9 \pm$ $0.1 \mathrm{eV}$ attributed to the oxygen atoms of amide and carboxylate groups $\left(\mathrm{HN}-\mathrm{C}=\mathrm{O} / \mathrm{COO}^{-}\right)$showing only one chemical form for the acidic groups of Gly-Pro adsorbed at the surface; at higher coverage, 35 minutes, this same peak is slightly downshifted at $531.7 \mathrm{eV} \pm 0.1 \mathrm{eV}$.

Concerning the N1s region, the analysis of the data is a bit more complicated, since the plasmon loss peak of $\mathrm{Ag} 3 \mathrm{~d}$ can be found around $400 \mathrm{eV}^{30}$. As a consequence, the $\mathrm{N} 1 \mathrm{~s}$ region already exhibits features on the clean Ag surface at 399 and $401 \mathrm{eV}$, which are usually assigned to different protonation states of amine groups and to amide groups, Figure SI4. Therefore, assignments of the different contributions observed for 10 and 35 minutes exposures are not straightforward. In fact, one cannot simply subtract the contribution of the $\mathrm{Ag}$ plasmon loss to obtain the contributions of nitrogen atoms from Gly-Pro. However, by applying certain constraint we were able to determine that most of the contribution due to Gly-Pro adsorbed appears as a single peak at $400.6 \pm 0.1 \mathrm{eV}\left(\mathrm{NH}_{2} / \mathrm{OC}-\right.$ $\mathrm{NH}$ ) for 10 minutes of exposure, and a small additional contribution at $399.7 \mathrm{eV}$ for an exposure of 35 minutes. XPS data thus confirm the chemical form of adsorbed Gly-Pro species at the $\mathrm{Ag}(110)$ surface: mainly as anionic molecule $\left(\mathrm{NH}_{2} / \mathrm{COO}^{-}\right)$for the monolayer regime. When looking at the C1s XPS data following adsorption of Gly-Pro on $\mathrm{Ag}(110)$, Figure SI5, one should note the absence of a strong contribution at high BE around $290 \mathrm{eV}$, showing the absence of protonated acidic species. These results confirmed that the Gly-Pro molecules are present mainly as anionic species when adsorbed on $\mathrm{Ag}(110)$.
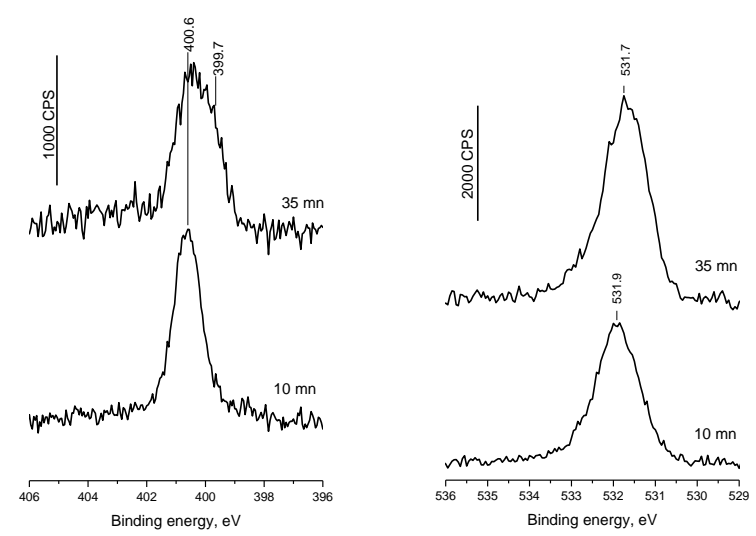

Figure 5: XPS high resolution spectra for the $\mathrm{N} 1 \mathrm{~s}$ and $\mathrm{O} 1 \mathrm{~s}$ regions for a 10 and 35 minute dose of Gly-Pro adsorbed on $\mathrm{Ag}(110)$.

STM experiments were also performed following adsorption of anionic Gly-Pro molecules on $\mathrm{Ag}(110)$. Figure 6 shows STM data obtained after 10 minutes of dose, which distinctly shows an arrangement in line along the axis [110]; these lines are arranged on a zig-zag fashion. When measuring the intermolecular distances on STM profiles, one can draw an adsorption model with zig-zag lines separated by an empty atomic row in the (001) crystallographic direction, forming a (3 2,0 2) chiral unit cell. Finally, from XPS data, we were able to calculate a local molecular density between 1.4 and 2.4 GlyPro molecules per $\mathrm{nm}^{2}$, which correspond to local coverage of 
$35 \%$ and $60 \%$ of a saturated monolayer of adsorbed GP molecules.
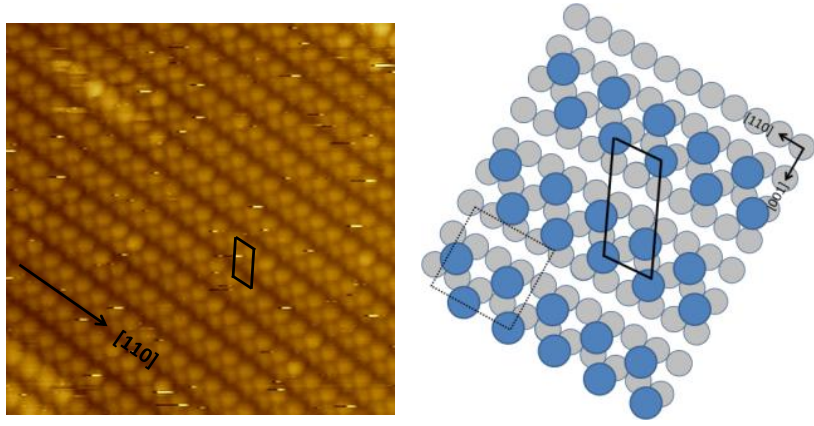

Figure 6: STM image of anionic GLY-PRO molecules adsorbed on $\mathrm{Ag}(110)$ showing a $(32,02)$ chiral unit cell. Corresponding adsorption model for Gly-Pro adsorbed as anionic molecules on $\mathrm{Ag}(110)$. On the schematic adsorption model, the dash square line represents an area of $1 \mathrm{~nm}^{2}$.

\section{Discussion}

Adsorption of Gly-Pro on $\mathrm{Au}(110)$ and $\mathrm{Ag}(110)$, characterized by XPS, PM-RAIRS and STM makes clear remarkable differences in the behaviours of these two metals:

On $\mathrm{Au}(110)$, after a short time of exposure (10 $\mathrm{min})$, the Gly-Pro molecules are mainly under the $\mathrm{NH}_{2} / \mathrm{COOH}$ or $\mathrm{NH}_{2} / \mathrm{COO}^{-}$chemical forms, with a minor amount of $\mathrm{NH}_{3}{ }^{+} / \mathrm{COO}^{-}$; RAIRS signal are weak, suggesting that the molecule, lies rather flat on the surface; a reasonable configuration for adsorbed molecules is that they bind to the gold surface via the peptidic $\mathrm{C}=\mathrm{O}$ group and one of the oxygen of the carboxylate, in agreement with the low intensity of the IR symmetric COO'. We correlate this chemical information to the complex bi-phasic domains imaged by STM: rows of dimers, coexisting with heptamers of Gly-Pro molecules. After longer time of exposure ( $35 \mathrm{~min}$ ), the average coverage attains the value of 2.4 Gly-Pro molecules $/ \mathrm{nm}^{2}$, still below one monolayer (which can be estimated at 4 molecules $/ \mathrm{nm}^{2}$ for the maximum local coverage); a higher coverage goes with a net increase of the N1s contribution at high energy, which indicates a higher fraction of molecules under a zwitterionic form. The hexagonal structure, now dominating on the surface, is likely formed by zwitterionic molecules; this can be explained by a higher proximity of the molecules to each other, arranged into heptamers, which facilitates proton exchange between $\mathrm{COOH}$ and $\mathrm{NH}_{2}$ groups, thus leading to zwitterionic molecules. As a matter of fact, and this is a key message of this contribution, an increase of the coverage of Gly-Pro on $\mathrm{Au}(110)$ changes not only the chemistry but also the organisation of the molecules, with aligned row of molecules rearranging into a denser patches of chiral hexagonal units. This example tends to show the tendency of gold to favour proton mobility from one molecule to another, provided that the coverage is high enough.

On $\mathrm{Ag}(110)$, adsorption of Gly-Pro is very different from what observed on $\mathrm{Au}(110)$; after $10 \mathrm{~min}$ of exposure, both XPS and RAIRS data suggest the presence of mainly anionic molecules with a small fraction of neutral ones; they organize in zig-zag lines, forming chiral cells; a longer exposure (35 min), induces a significant increase of the coverage (1.4 to 2.4 Gly-Pro molecules $/ \mathrm{nm}^{2}$ ), with, however, neither chemical change, nor modification of the arrangement of the molecule.

At that point, it is of course tempting to recall the data on $\mathrm{Cu}(110)$ : under similar conditions, Gly-Pro also adsorbs under an anionic form, and formed rows of aligned molecules ${ }^{27}$; the little difference lies in the interaction of the surface with the nitrogen atom of the terminal $\mathrm{NH}_{2}$ group, occurring from the beginning of the adsorption on copper, but only after a longer time of exposure on silver. These findings show that $\mathrm{Ag}$ and $\mathrm{Cu}$, which both are reactive metals, facilitate the acid deprotonation followed by the direct interaction of the oxygen atoms of the carboxylate groups; they also favour an interaction of nitrogen with the surface.

The interaction of amino acids, under their ionic form, with copper is, according to us, a rather general rule ${ }^{4,10}$. It has been indeed shown for glycine, alanine, leucine, lysine, histidine, to cite a few, on $\mathrm{Cu}(110)^{6,7,20,22,31-33}$. Note the particular example of proline, which has an $\mathrm{N}$ atom in the pyrrolidine rings and binds to the $\mathrm{Cu}(110)$ surface via the oxygen atoms of the deprotonated carboxylate group and also via the $\mathrm{N}$ atom of the ring, thus confirming the affinity of both oxygen and nitrogen with copper. ${ }^{34}$

Interestingly, methionine, an amino acid bearing a sulfur atom along its side chain, was also adsorbed on both $\mathrm{Au}(111)$ and $\mathrm{Cu}(110), \mathrm{Cu}(111)$ and $\mathrm{Ag}(111)^{17-19,35,36}$, thus enabling to tackle the influence of the nature of the substrate upon adsorption mode (not forgetting the fact that differences in the surface structure may also account for differences in the adsorption modes). As expected, on copper, methionine undergoes a deprotonation of its $\mathrm{COOH}$ groups at any coverage, thus adopting an anionic form. However, on $\mathrm{Au}(111)$, methionine adopts a zwitterionic form and interacts preferentially via one oxygen of the carboxylate but not via the nitrogen ${ }^{17,35}$. Interestingly is the 2D structures of adsorbed methionine on these surfaces; for all (111) surfaces, the molecules aligned as lines of dimers along the crystallographic axes, regardless of their chemistry: zwitterionic for $\mathrm{Au}$ and $\mathrm{Ag}$, against anionic for $\mathrm{Cu}$. This clearly shows that the structure of the surface, along with the anchoring geometry, leads to the same 2D arrays. While the difference of structure between $\mathrm{Cu}(111)$ and $\mathrm{Cu}(110)$, at constant chemistry (i.e. anionic) goes from lines of dimers to random adsorption, respectively ${ }^{17,18}$. Finally, glutamic acid (Glu) is another amino acid whose adsoption process was carefully characterized on $\mathrm{Ag}$ well defined surfaces. On $\mathrm{Ag}(110)$, Glu adsorbs in its anionic form, only one out of the two carbonyl groups being deprotonated; XPS data also show the interaction of the $\mathrm{N}$ atom of the $\mathrm{NH}_{2}$ group with the surface ${ }^{37,38}$. Note that, on $\mathrm{Ag}(111)$, Glutamic acid appears to be preferentially under a zwitterionic form. Once again, one sees the possible role of the surface structure on the chemistry of adsorption. 


\section{Conclusions}

We would not end this paper without recommending being very cautious in the prediction or comparison regarding the behaviours of amino acids or small peptides with metals. Chemistry and structural arrangement likely very much depend on experimental conditions, pressure and time of exposure, surface defects, time of relaxation of the system before analysis. Let's cite V. Feyer and his group who performed a huge work on the adsorption of amino acids and of small peptides on metals; they, in particular, showed that Glycil-Glycil and L-Histidine interact with $\mathrm{Cu}(110)$ via their carboxylate groups (and nitrogen in some cases); they also propose that on $\mathrm{Au}(111)$, though less reactive than copper, histidine molecules also interact with their carboxylate groups ${ }^{39}$. We have no explanation for the behaviour of histidine on $\mathrm{Au}(111)$, in terms of acid deprotonation, different from that of Gly-Pro on $\mathrm{Au}$ (110) (the surface geometry is different, but could it be the only reason ?).

Another example, in disagreement with our finding is that of glycine which, according to Zhao et al., does not chemisorb on clean $\mathrm{Ag}$ at $300 \mathrm{~K}$; the authors ascribe this to the inability of this substrate to deprotonate the acid group ${ }^{40}$. These systems are indeed complex!

Though a number of questions still pending, it is the first time to our knowledge, that one small peptide was adsorbed on the same planar surface of three different metals. Analyses by XPS and RAIRS data provided us with an undoubtful characterization of the adsorbed species, neutral, anionic or zwitterionic, and this depends on the nature of the metal, and on the coverage as far as gold is concerned.

Moreover, STM images enabled us to propose reasonable pictures of Gly-Pro layer structures. On $\mathrm{Au}(110)$ and on $\mathrm{Ag}(110)$, Gly-Pro molecules form lines and create chiral cells; on $\mathrm{Au}(110)$, and only on that surface, longer time of exposure or longer time on the surface induces a rearrangement, likely more stable, into heptamers where molecules are in close vicinity to each other; such a reorganization might be correlated to the reconstruction of the $\mathrm{Au}(110)$ surface.

These examples also demonstrate the need to combine complementary surface science techniques to get a reasonable picture of the behaviour of peptides at a metal surface.

\section{Experimental}

\section{Materials}

Gly-Pro from Bachem, was used as received. For sublimation evaporation, the peptide was deposited in a small glass tube and resistively heated with a W/Th wire wrapped around the crucible. The evaporator was initially separated from the main chamber by a gate valve and differentially pumped by a turbomolecular pump. Before sublimation, the Gly-Pro powder was outgassed at $390 \mathrm{~K}$. It was then heated to $400 \mathrm{~K}$ and introduced in the chamber, where the glass tube was placed in front of the gold, silver and copper single crystals. The dosing pressure was maintained around $2 \times 10^{-9}$ Torr during the deposition of the adlayer.

The gold $\mathrm{Au}(110)$ crystal (10 $\mathrm{mm}$ diameter, $2 \mathrm{~mm}$ thick) and the silver $\mathrm{Ag}(110)$ crystal $(12 \mathrm{~mm}$ diameter, $2 \mathrm{~mm}$ thick were provided by Surface Preparation Laboratory (The Netherlands) with a purity of $99.99 \%(4 \mathrm{~N})$, and alignment accuracies of $0.1^{\circ}$.

\section{STM experiments}

Scanning Tunnelling Microscopy experiments were conducted in a an Omicron Vakuumphysik chamber XA VT-STM with facilities for STM, LEED, AES and sample cleaning and a base pressure of $5 \times 10^{-11}$ Torr. The single crystals were cleaned by cycles of $\mathrm{Ar}^{+}$ion sputtering $\left(\mathrm{P}_{\mathrm{Ar}}=7 \times 10^{-5} \mathrm{Torr}, 600 \mathrm{~V}\right.$ during 15 minutes), flashing and annealing to $850 \mathrm{~K}$ for 30 minutes. Before STM experiments, the deposition of Gly-Pro was carried out at room temperature. STM experiments were carried out with the sample at room temperature, the images were acquired in constant current mode, and not correction was applied except a plane fit correction.

\section{PM-RAIRS and XPS experiments}

The $\mathrm{Au}(110)$ and $\mathrm{Ag}(110)$ single crystals were mounted in a multi-technique Ultra High Vacuum UHV chamber, base pressure $1 \times 10^{-10}$ Torr, with PM-RAIRS, LEED, and XPS facilities. The crystals were cleaned by cycles of $\mathrm{Ar}^{+}$ion sputtering $\left(\mathrm{P}_{\mathrm{Ar}}=\right.$ $5 \times 10^{-5}$ Torr, $3 \mathrm{kV}$, during 5 minutes), flashing, and annealing to $850 \mathrm{~K}$ for 10 minutes. The surface structure and cleanliness were monitored by LEED and XPS before and after adsorption experiments.

Adsorption of Gly-Pro was monitored in-situ by PM-IRRAS; a Nicolet 5700 spectrometer was interfaced with the UHV chamber, together with a liquid nitrogen-cooled MCT detector. All spectra were recorded in-situ, after stopping the dosing of Gly-Pro by closing a gate valve between the UHV chamber and Knüdsen cell. All spectra were recorded at $8 \mathrm{~cm}^{-1}$ resolution by co-addition of 1024 scans (time of acquisition: $10 \mathrm{~min}$ ). The modulating frequency was set for a maximal sensitivity at 1500 $\mathrm{cm}^{-1}$.

The sample was analyzed by X-ray photoemission spectroscopy using a SPECS GmbH (Berlin, Germany) Phoibos 100-1D delay line detector hemispherical analyzer and a monochromatized AlK $\alpha$ X-Ray Source (1486.6 eV). After recording a broad range spectrum (pass energy $100 \mathrm{eV}$ ), high resolution spectra were recorded for the $\mathrm{N} 1 \mathrm{~s}, \mathrm{C} 1 \mathrm{~s}$ and $\mathrm{O} 1 \mathrm{~s}$ core levels (pass energy $20 \mathrm{eV}$ ). High-resolution XPS conditions have been fixed:" Fixed Analyser Transmission" analysis mode, a 7 × $20 \mathrm{~mm}$ entrance slit; leading to a resolution of $0.1 \mathrm{eV}$ for the spectrometer, and an electron beam power of $150 \mathrm{~W}(15 \mathrm{kV}$ and $10 \mathrm{~mA})$. The spectra were fitted using Casa XPS v.2.3.17 Software [Casa Software Ltd., UK] and applying a Gaussian/Lorentzian ratio $\mathrm{G} / \mathrm{L}$ equal to $70 / 30$.

\section{Notes and references}

1.
K. H. Ernst, Phys. Status Solidi B, 2012, 249, 2057-2088. 
J. J. Gray, Curr. Opin. Struct. Biol., 2004, 14, 110-115. B. Kasemo, Surf. Sci., 2002, 500, 656-677.

S. M. Barlow and R. Raval, Surf. Sci. Rep., 2003, 50, 201-341. Y. J. Chabal and S. B. Christman, Phys. Rev. B, 1984, 29, 6974-6976.

Q. Chen, D. J. Frankel and N. V. Richardson, Langmuir, 2002, 18, 3219-3225.

Q. Chen, D. J. Frankel and N. V. Richardson, Surf. Sci., 2002 497, 37-46.

Q. Chen and N. V. Richardson, Nature Materials, 2003, 2, 324-328. 2000, 16, 9287-9293. 2015, 70, 449-553.

Hasselström, O. Karis, M. Weinelt, N. Wassdahl, A. Nilsson,

M. Nyberg, L. G. M. Pettersson, M. G. Samant and J. Stöhr, Surf. Sci., 1998, 407, 221-236.

V. Humblot, C. Méthivier and C.-M. Pradier, Langmuir, 2006 22, 3089-3096.

V. Humblot, C. Méthivier, R. Raval and C.-M. Pradier, Surf. Sci., 2007, 601, 4189-4194.

M. O. Lorenzo, S. Haq, T. Bertrams, P. Murray, R. Raval and C. J. Baddeley, J. Phys. Chem. B, 1999, 103, 10661-10669.

E. M. Marti, C. Methivier, P. Dubot and C. M. Pradier, J. Phys Chem. B, 2003, 107, 10785-10792.

E. M. Marti, C. Methivier and C. M. Pradier, Langmuir, 2004 20, 10223-10230.

C. Méthivier, V. Humblot and C.-M. Pradier, Surf. Sci., 2015, 632, 88-92.

A. Schiffrin, J. Reichert, Y, Pennec, W. Auwarter, A. WeberBargioni, M. Marschall, M. Dell'Angela, D. Cvetko, G. Bavdek, A. Cossaro, A. Morgante and J. V. Barth, J. Phys. Chem. C, 2009, 113, 12101-12108.

A. Schiffrin, A. Riemann, W. Auwarter, Y. Pennec, A. WeberBargioni, D. Cvetko, A. Cossaro, M. Alberto and J. V. Barth, Proc. Natl. Acad. Sci. USA, 2007, 104, 5279-5284.

S. M. Barlow, K. J. Kitching, S. Haq and N. V. Richardson, Surf Sci., 1998, 401, 322-335.

M. Nyberg, M. Odelius, A. Nilsson and L. G. M. Pettersson, J. Chem. Phys., 2003, 119, 12577-12585.

V. Feyer, O. Plekan, T. Skala, V. Chab, V. Matolin and K. C. Prince, J. Phys. Chem. B, 2008, 112, 13655-13660.

C. Méthivier, V. Humblot and C.-M. Pradier, J. Phys. Chem. B, 2016.

D. Costa, L. Savio and C.-M. Pradier, J. Phys. Chem. B, 2016, 120, 7039-7052.

A. Vallée, V. Humblot, C. Méthivier and C.-M. Pradier, Surf. Sci., 2008, 602, 2256-2263.

A. Vallée, V. Humblot, C. Méthivier and C.-M. Pradier, J. Phys. Chem. C, 2009, 113, 9336-9344.

C. Méthivier, H. Cruguel, D. Costa, C.-M. Pradier and V.Humblot., Langmuir, 2016, 32, 13759-13763.

C. Méthivier, V. Lebec, J. Landoulsi and C.-M. Pradier, J. Phys. Chem. C, 2011, 115, 4041-4046.

C. Méthivier, V.Humblot and C.-M. Pradier, J. Phys. Chem. C, 2016, 120, 27364-27368.

J. F. Moulder, W. F. Stickle, P. E. Sobol and K. D. Bomben Handbook of X-ray Photoelectron Spectroscopy, Eden Prairie, MN, 1992.

S. M. Barlow, S. Haq and R. Raval, Langmuir, 2001, 17, 32923300.

M. Canepa, L. Lavagnino, L. Pasquali, R. Moroni, F. Bisio, V. De Renzi, S. Terreni and L. Mattera, J. Phys.: Condens. Mat., 2009, 21, 264005.

V. Feyer, O. Plekan, N. Tsud, V. Lyamayev, V. Chab, V. Matolin, K. C. Prince and V. Carravetta, J. Phys. Chem. C, 2010, 114, 10922-10931.

E. Mateo Marti, S. M. Barlow, S. Haq and R. Raval, Surf. Sci., 2002, 501, 191-202.
35. V. Humblot, F. Tielens, N. B. Luque, H. Hampartsoumian, C. Méthivier and C.-M. Pradier, Langmuir, 2014, 30, 203-212.

36. A. Naitabdi and V. Humblot, Appl. Phys. Lett., 2010, 97 223112.

37. M. Smerieri, L. Vattuone, T. Kravchuk, D. Costa and L. Savio Langmuir, 2011, 27, 2393-2404.

38. M. Smerieri, L. Vattuone, M. Rocca and L. Savio, Langmuir, 2013, 29, 6867-6875.

39. V. Feyer, O. Plekan, N. Tsud, V. Chab, V. Matolin and K. C. Prince, Langmuir, 2010, 26, 8606-8613.

40. X. Y. Zhao, H. Yan, X. W. Tu, R. G. Zhao and W. S. Yang Langmuir, 2003, 19, 5542-5545. 


\section{Electronic Supplementary Information (ESI)}

Table SI1: atomic percentage for $\mathrm{N} 1 \mathrm{~s}$ and $\mathrm{O} 1 \mathrm{~s}$ regions as a function of GLY-PRO exposure / $\mathrm{Au}(110)$.

\begin{tabular}{|l|l|l|l|l|}
\hline N1s & \multicolumn{3}{|l|}{$\begin{array}{l}402 \mathrm{eV} \\
\mathrm{NH}_{3}{ }^{+}\end{array}$} & $\begin{array}{l}400 \mathrm{eV} \\
\mathrm{NH}_{2} / \mathrm{NH}\end{array}$ \\
\cline { 2 - 5 } & $10 \mathrm{~min}$ & 20.3 & 79.4 \\
\cline { 2 - 5 } & $35 \mathrm{~min}$ & 32.4 & 67.6 \\
\hline O1s & & $\begin{array}{l}533 \mathrm{eV} \\
\mathrm{C}-\mathrm{OH}\end{array}$ & $\begin{array}{l}532 \mathrm{eV} \\
\mathrm{COOH}\end{array}$ & $\begin{array}{l}532 \mathrm{eV} \\
\mathrm{HN}-\mathrm{C}=\mathrm{O} / \mathrm{COO}^{-}\end{array}$ \\
& & 19.5 & 19.5 & 61.0 \\
\cline { 2 - 5 } & $10 \mathrm{~min}$ & 17.7 & 17.7 & 64.6 \\
\cline { 2 - 5 } & $35 \mathrm{~min}$ & 17 & \multicolumn{2}{|c|}{} \\
\hline
\end{tabular}

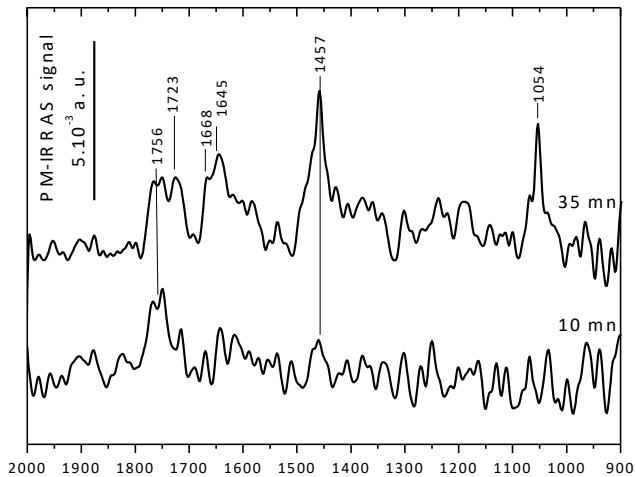

$$
\text { wavenumber, } \mathrm{cm}^{-1}
$$

Figure SI1: PM-RAIRS spectra of Gly-Pro molecules adsorbed at Room Temperature on $\mathrm{Au}(110)-(1 \times 2)$ as a function of increasing coverage.

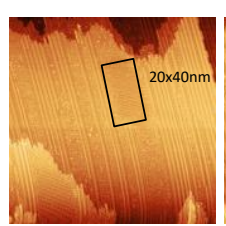

30 minutes

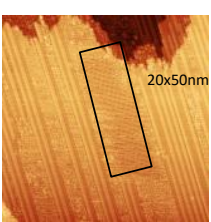

45 minutes

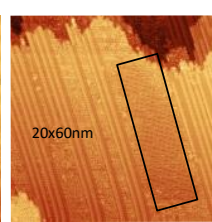

60 minutes

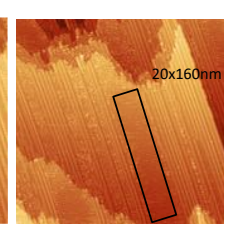

150 minutes
Figure SI2: STM image series obtained by scanning the same area for up to 3 hours showing the evolution of 2D surface structures.

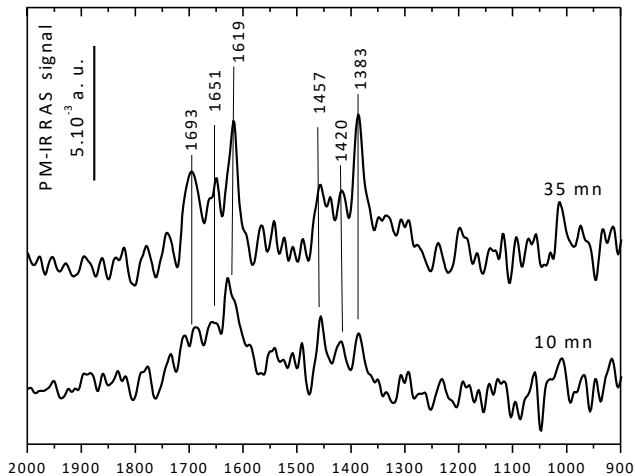

wavenumber, $\mathrm{cm}^{-1}$

Figure SI3: PM-RAIRS spectra of Gly-Pro molecules adsorbed at Room Temperature on $\mathrm{Ag}(110)$ as a function of increasing coverage.
$\mathrm{Ag}$

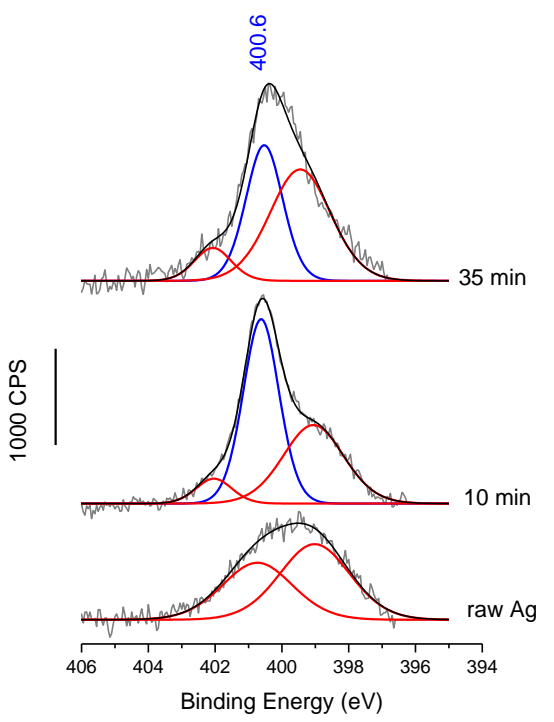

Figure S14: XPS high resolution spectra for the N1 s of raw clean $\mathrm{Ag}(110)$ surface, and for a 10 and 35 minute dose of GlyPro.
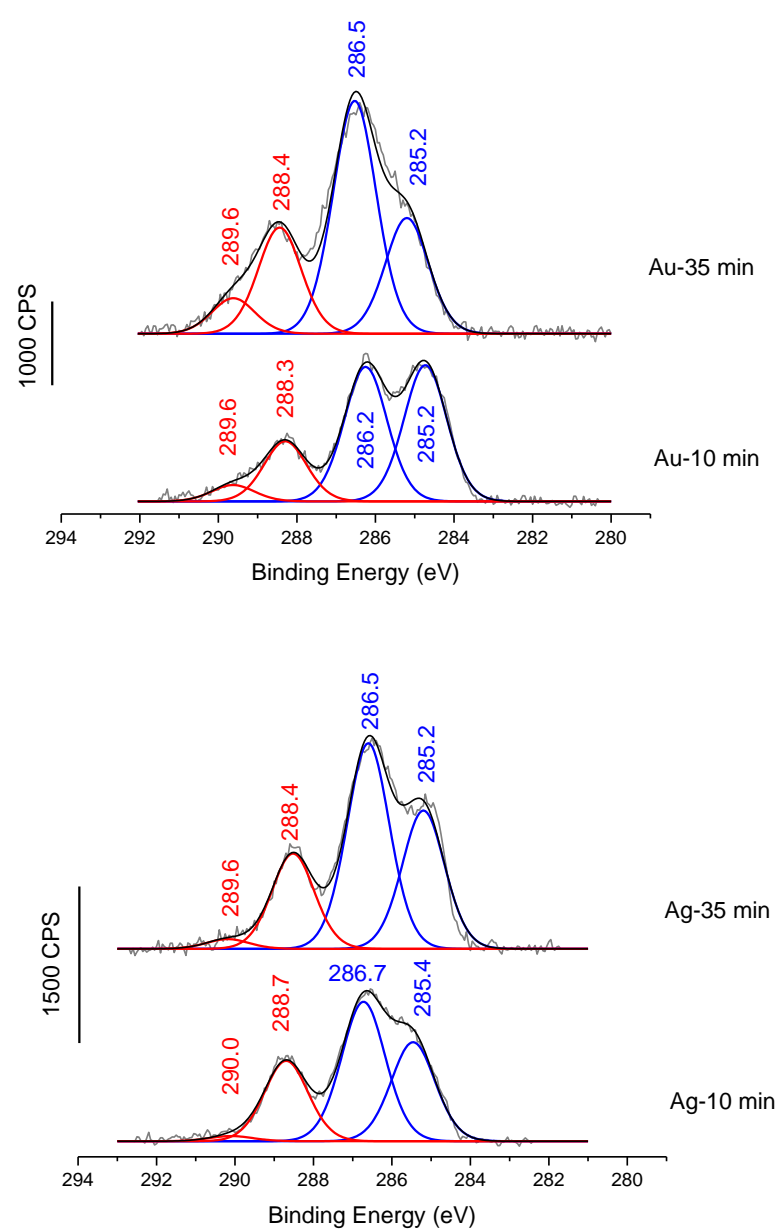

Figure SI5 C1s XPS high resolution spectra obtained after GLYPRO exposure of 10 and 35 minutes on $\mathrm{Au}$ and $\mathrm{Ag}$ surfaces, respectively. 